\title{
ECOLOGY, BEHAVIOUR AND AREA-WIDE CONTROL OF THE FLOODWATER MOSQUITO Aedes sticticus, WITH POTENTIAL OF FUTURE INTEGRATION OF THE STERILE INSECT TECHNIQUE
}

\author{
J. O. LUNDSTRÖM ${ }^{1,2}$, M. L. SCHÄFER ${ }^{2}$ AND P. \\ KITTAYAPONG ${ }^{3,4}$
}

\begin{abstract}
${ }^{I}$ Zoonosis Research Center, Department of Medical Biochemistry and Microbiology, Uppsala University, Box 582,SE-75123 Uppsala, Sweden; jan.lundstrom@mygg.se ${ }^{2}$ Biologisk Myggkontroll, Nedre Dalälven Utvecklings AB, Vårdsätravägen 5, SE75646 Uppsala, Sweden

${ }^{3}$ Center of Excellence for Vectors and Vector-Borne Diseases, Faculty of Science, Mahidol University, 999 Phuttamonthon 4 Road, Nakhon Pathom 73170, Thailand ${ }^{4}$ Department of Biology, Faculty of Science, Mahidol University, 272 Rama VI Road, Bangkok 10400, Thailand
\end{abstract}

\begin{abstract}
SUMMARY
The strategy of aerial control of the floodwater mosquito Aedes sticticus (Meigen) in the floodplains of River Dalälven, central Sweden, was developed to directly address specific larval breeding areas in temporary flooded wet meadows and swamps. Using the Bti-based larvicide VectoBac $\mathrm{G} \AA$, a very strong reduction of larval abundance is achieved, resulting in a massive decrease of blood-seeking females that could otherwise spread from the wetlands to feast on blood from humans and animals within $5 \mathrm{~km}$ or more from the larval biotopes. However, there is also a political demand to reduce the usage of the control agent through hypothetical alternatives, such as cattle grazing and mowing of the meadows, as well as hydrological changes of the River Dalälven. An evaluation of these measures showed that they are either insufficient or unrealistic in reducing floodwater mosquito abundance. Thus, we searched for other potential population suppression methods. Using the criteria of efficacy, environmental neutrality and compatibility within an integrated suppression approach, we conclude that Sterile Insect Technique (SIT) and the Incompatibility Insect Technique (IIT) would qualify for a pilot-scale test of their feasibility for the integrated control of the floodwater mosquito Ae. sticticus. The SIT and the IIT are similar strategies involving the release of sterile males which mate with local fertile females and result in infertile eggs. Prerequisites for a sterile male strategy to control Ae. sticticus include: a laboratory colony of the species, a facility for mass-rearing of mosquitoes, the sterilisation of males, a transport strategy, a dispersal system, assay systems for several life stages, and a method capable of reducing the population of this superabundant
\end{abstract}

J. Hendrichs, R. Pereira and M. J. B. Vreysen (eds.), Area-Wide Integrated Pest Management: Development and Field Application, pp. 433-459. CRC Press, Boca Raton, Florida, USA.

(C) 2021 IAEA 
species before commencing the sterile male release. One factor in favour of implementing the SIT or IIT against Ae. sticticus is that mating occurs in or near well-defined larval breeding areas with specific relation to flood events. Another factor in favour of the SIT or the IIT is the availability of existing methods to measure gender, larvae and egg abundance. Also, existing Bti-treatments can substantially lower the population size before sterile male release. Other prerequisites, like the successful colonization of $A e$. sticticus will require more tests and adaptations of existing mosquito rearing protocols. A pilot study is suggested for an isolated study area, protected from reinvasion by Ae. sticticus-females and included in routine Bti-treatments.

Key Words: Aedes sticticus, Sweden, River Dalälven, floodplains, wetlands, Bacillus thuringiensis israelensis (Bti), larvicide, VectoBac G, SIT, Incompatibility Insect Technique (IIT)

\section{INTRODUCTION}

Sweden, located in the north of Europe, is a country where mosquitoes are pervasive. While mosquito abundances were assumed to be highest in the northernmost part of the country, mosquito diversity increases towards the south (Schäfer and Lundström 2001). Generally, snow pool mosquitoes, e.g. Aedes communis (De Geer) and Aedes punctor (Kirby) are the most common species found throughout the country. Nuisance by these univoltine mosquito species can be severe, but occurs mainly in spring and early summer, followed by rapidly declining numbers.

When people in the River Dalälven floodplains in central Sweden complained about mosquito problems in the 1980's and 1990's, they were not taken seriously and often met with the conventional wisdom that mosquito problems are much more severe in the north. For a long time, the actual nuisance mosquito species was unknown, since knowledge on the mosquito fauna in the River Dalälven region was insufficient. In a study from 1985, the floodwater mosquito Aedes rossicus Dolbeskin, Gorickaja and Mitrofanova was reported as the most abundant species (Jaenson 1986). Ten years later, researchers studying Sindbis virus in the area needed to use protective clothing due to the enormous abundance of mosquitoes, but no general identification of nuisance species was performed (Lundström et al. 1996).

In the summer of 2000, we studied mosquito species diversity in the central part of the region at Lake Färnebofjärden, which coincided with one of the worst mosquito nuisance years due to massive floods. Mosquito sampling with CDC miniature light traps baited with dry ice resulted in enormous numbers (up to 61500 mosquitoes per trap and night) and the predominant species was Aedes sticticus (Meigen) (Schäfer et al. 2008). This can be compared to the maximum number of 4500 mosquitoes per trap and night (trap-night) from a wetland in northern Sweden (unpublished information).

The people of the River Dalälven floodplains were desperate, and children had to be transported away from the area by buses to be able to swim and play outside during their summer vacation. Media awakened and the mosquito-infected towns in the region became known in the whole country. The major breakthrough in the people's struggle to continue living in this area was a visit from the Minister of Environment, Mr. Kjell Larsson, who is still the only minister to experience massive floodwater mosquito nuisance. His words, "You cannot have it like that" became historic; and resulted in the development of the first professional mosquito control in Sweden.

The identification of the flood-water mosquito Ae. sticticus as the main cause of the horrendous nuisance made it the prime target species for control. Larviciding with 
Bacillus thuringiensis israelensis (Bti) was the method of choice for its low environmental impact, efficacy, and practical application over large areas.

During recent years, political pressure has created a demand for alternative methods to control this superabundant day-active and long-range dispersing mosquito, motivating us to search for new, less intrusive mosquito control methods suitable for area-wide use in natural wetlands.

Below we describe development of our high-tech GIS-based strategy of direct Btibased larval control (Section 2), the way forward for adapting SIT-based birth control for area-wide control of Ae. sticticus in natural wetlands (Section 5), and a section on perspectives (Section 6).

\section{DEVELOPING AREA-WIDE CONTROL OF Aedes sticticus IN NATURAL WETLANDS}

\subsection{The River Dalälven Floodplains}

The River Dalälven covers a catchment area of approximately $29000 \mathrm{~km}^{2}$, originating in the mountains along the Swedish-Norwegian border and outflowing into the Baltic Sea (Fig. 1).

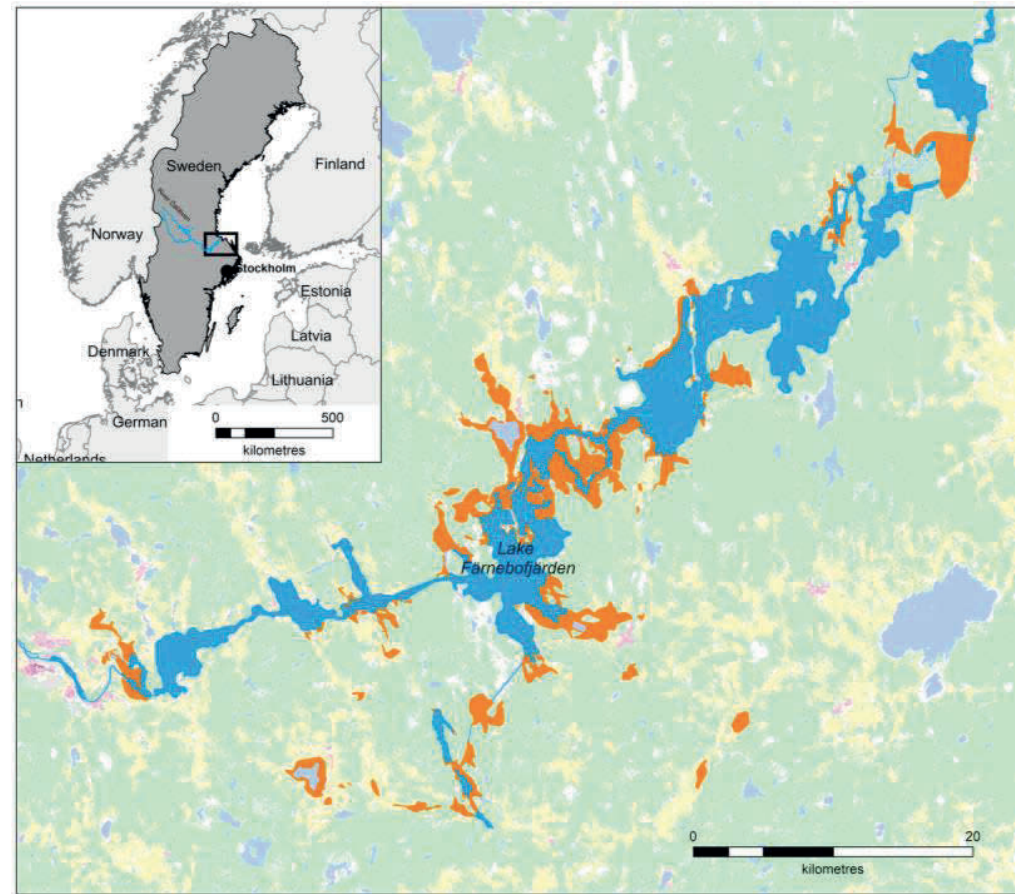

Figure 1. The location of the River Dalälven in central Sweden (inlet) and the floodplains with its many lakes in the lower part of River Dalälven. The areas with permit for mosquito control treatments by Bti for 2019 are shown in orange. 
The River Dalälven, with its main branches Västerdalälven and Österdalälven, is partly regulated for production of hydro-electric power. In its lower part, the river forms a chain of lakes connected by rapids. In these floodplains, temporary flooded marshes, wet meadows and alder swamps cover several thousand hectares (ha) and most of this area is protected by both national regulations and EU-regulations. Water level fluctuations are most dramatic and frequent in Lake Färnebofjärden, which is protected as a National Park and contains several protected Nature Reserves and Natura 2000 areas. Flooding is induced by melting snow and/or heavy rainfall that causes increased waterflow in River Dalälven and other smaller watercourses in the floodplain area, and the water level can increase by $2.0 \mathrm{~m}$ or more in the Lake Färnebofjärden area. This is an area of enormous mosquito abundance and a hotspot for mosquito diversity (Schäfer et al. 2018).

\subsection{Ecology and Behaviour of Aedes sticticus}

Floodwater mosquitoes, in particular Ae. sticticus and Aedes vexans (Meigen), are the predominant mosquito species in areas influenced by large rivers or lakes with water level fluctuations in adjacent lowlands (Becker and Ludwig 1981; Merdic and Lovakovic 2001; Minar et al. 2001; Schäfer et al. 2008). These mosquito species oviposit their eggs on moist soil, into small depressions or in moss, which are subsequently flooded with rising water levels (Horsfall et al. 1973). The eggs are in diapause during autumn, winter and early spring, and remain viable for at least 4 years (Gjullin et al. 1950; Horsfall et al. 1973) but probably longer. When the eggs are flooded by shallow water, hatching of larvae is triggered by water temperature and decreasing oxygen level. After melting of the snow, water temperature needs to exceed about $8^{\circ} \mathrm{C}$ for eclosion of Ae. sticticus eggs (Becker et al. 2010), thus avoiding larval hatching during the cold seasons. Flowing water inundating the wetlands is oxygen-rich, but once the water in the inundated areas becomes stagnant, oxygen levels decrease due to bacterial degradation processes. This signals the appropriate time for larvae to hatch from the eggs. Newly hatched larvae no longer risk being carried away by flowing water, and the bacterial activity ensures adequate food supply (Becker et al. 2010).

The synchronised hatching of Ae. sticticus larvae after a flood results in massive amounts of larvae at about the same time, although not all eggs hatch during the same flood event. This so-called 'hatching-in-installment' ensures survival of the population in case the larval breeding site dries out before development to adults is completed (Wilson and Horsfall 1970; Becker 1989). The development of the larvae to pupae and emergence of adults is temperature-dependent (Trpis and Shemanchuk 1970; Becker 1989). The males emerge about one day before the females and need to rotate their hypopygium to be ready to mate. Females mate only once and store sufficient sperm in their spermathecae for fertilizing several egg batches (Becker et al. 2010). After mating, the females start searching for a blood meal to develop eggs. The blood-seeking Ae. sticticus females are known for their long-distance dispersal behaviour, covering distances of at least $10 \mathrm{~km}$ (Brust 1980; Sudarić Bogojević et al. 2011). 
Floodwater mosquitoes are multivoltine and each flood during spring and summer can produce a new generation of mosquitoes. Together with their capability for massreproduction, this explains the enormous numbers and the lengthy occurrence of floodwater mosquito nuisance over several months in summer and fall. These mosquitoes cause an enormous nuisance affecting every aspect of living, working and visiting the mosquito-infested areas, as well as the health of the human and livestock populations, resulting in reduced property prices.

\subsection{Area-wide Control of Ae. sticticus using Bti}

In the summer of 2000, when people once again were attacked by horrendous numbers of floodwater mosquitoes, the desperate call for help to reduce mosquito nuisance became major and repetitive news in the media at all levels. Officials of one of the seven affected municipalities then made the decision to initiate professional mosquito control operations and the other six municipalities followed the lead.

It was rapidly clear that the only possible and realistic solution was larviciding using a Bti-product. In view of the multitude of protected areas in the River Dalälven floodplains and the high environmental awareness in Sweden, chemical control or the application of less specific control agents were excluded. When applied correctly, Btiproducts are highly selective against target mosquitoes without any known negative effects on non-target organisms or the environment (Lundström et al. 2010a, 2010b; Caquet et al. 2011; Lagadic et al. 2013, 2016). We decided to use the ready-to-use product VectoBac $\mathrm{G}{ }^{\circledR}$, consisting of corn-cob granules coated with Bti attached to the granules with corn oil.

Successful application of VectoBac $G \AA$ requires detailed knowledge on the ecology of the target species to direct the treatments to the correct sites at the appropriate time. Thus, the first step for the programme against Ae. sticticus was precise mapping of the larval breeding sites. Mapping in the field started in the autumn of 2000 using a high precision GPS, amounting to a total area of 1170 ha near the two most affected towns Österfärnebo and Tärnsjö. This method was based on vegetation as indicators for temporary flooded areas and was very labour-intensive.

To speed up the mapping process and get more precise information on the geographic extent of inundations, another approach was needed. We decided to develop a high-precision digital elevation model (DEM) based on laser-scanning of the relevant areas. In 2003, the entire lower part of the River Dalälven was covered by air-borne laser-scanning. The multitudinous point measurements of the laserscanning were used to create a DEM with sufficient resolution to discern height with centimetre precision. Since then, we use modelling with this DEM to discern the shallow flooded areas harbouring Ae. sticticus larvae, and to prepare the polygons to precisely direct the VectoBac $\mathrm{G} \AA$ larval treatments.

The first mosquito control operation in Sweden was carried out in 2002 and covered in total 443 ha. In the beginning, only temporary flooded areas outside nature reserves, the national park and close to the towns of Österfärnebo and Tärnsjö were included (Fig. 2). 


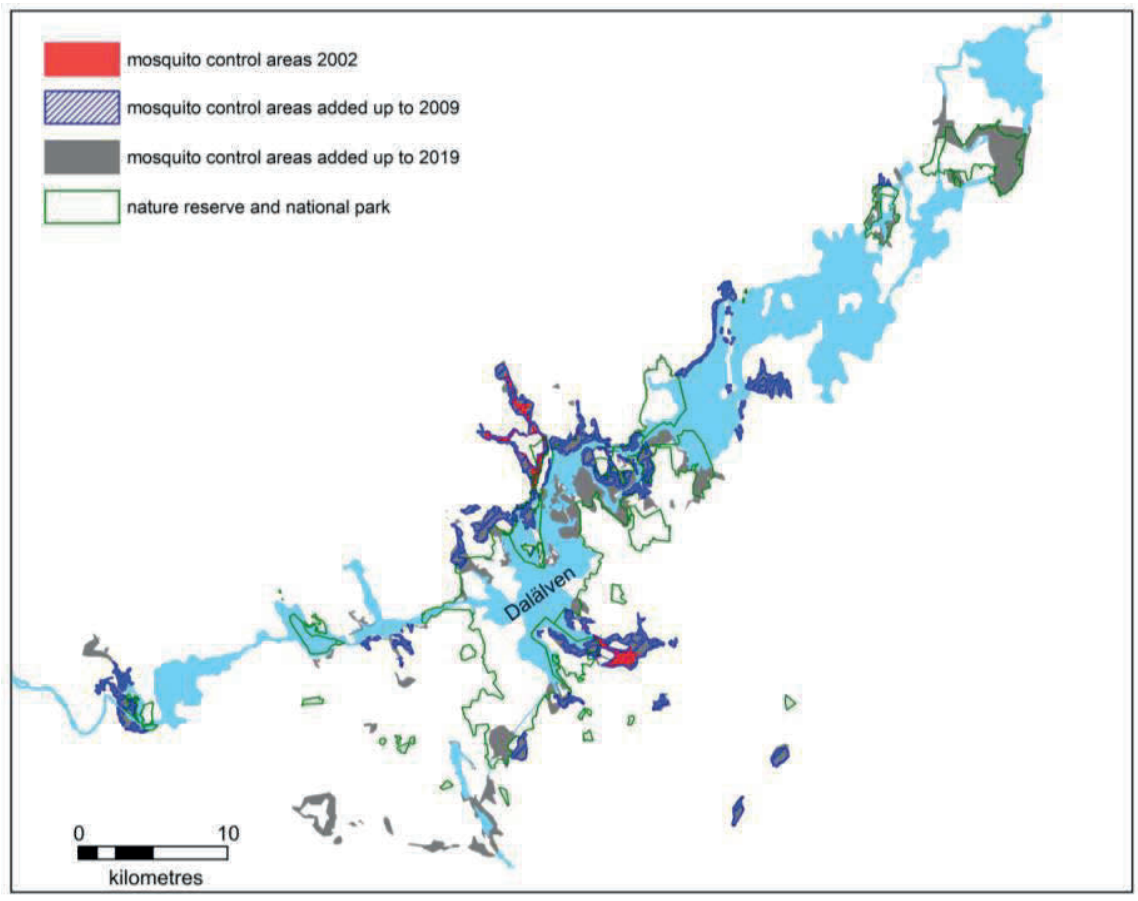

Figure 2. The gradual increase of areas with permissions for mosquito control based on dispersal of VectoBac $G{ }^{\circledR}$ granules by helicopter in natural wetlands, exemplified by the years 2002, 2009 and 2019. In 2009, some protected areas were finally included because of a case won at the Supreme Environmental Court of Sweden.

Over the years, we gradually increased the coverage of treatment areas, and another milestone was reached in 2009 with the first permission for treatments in protected areas (Fig. 2). This achievement however required a court case that was decided in favour of treatments at the Supreme Environmental Court of Sweden.

Since 2016, we have permission to treat more than 10000 ha of swamps, marshes and meadows and the single largest treatment so far covered 4411 ha in May 2018. The need for VectoBac $G^{\circledR}$ application varied between the years, from no application at all during some years when no floods took place, e.g. 2004 and 2017, to a maximum total of 9345 ha in 2015 (Fig. 3). In addition, the applied dosage of VectoBac $G^{\circledR}$ was gradually reduced from $15-17 \mathrm{~kg} /$ ha during the first years to $11-13 \mathrm{~kg} /$ ha during recent years. This dose reduction was achieved by technical improvements regarding the helicopter application and navigation system used.

\subsection{Routine Control Operations}

From middle of April until end of August, the water flow fluctuations of the River Dalälven is followed seven days per week, and through collaboration with water regulation authorities we have access to a professional water flow prognosis. If there 
is an indication of rising water levels in the lakes of the floodplain, actual inundations are monitored in the field and the presence of newly hatched larvae of the target floodwater mosquitoes assessed. It is crucial to find the first-instar larvae of Ae. sticticus as early as possible to maximize the time window for Bti-treatments. During these first days, several two person teams visit selected sites to measure the abundance of mosquito larvae with a standard larval dipper and to map the waterline with a handheld high-precision GPS. These field-collected data provide the baseline for all decisions on treatments.

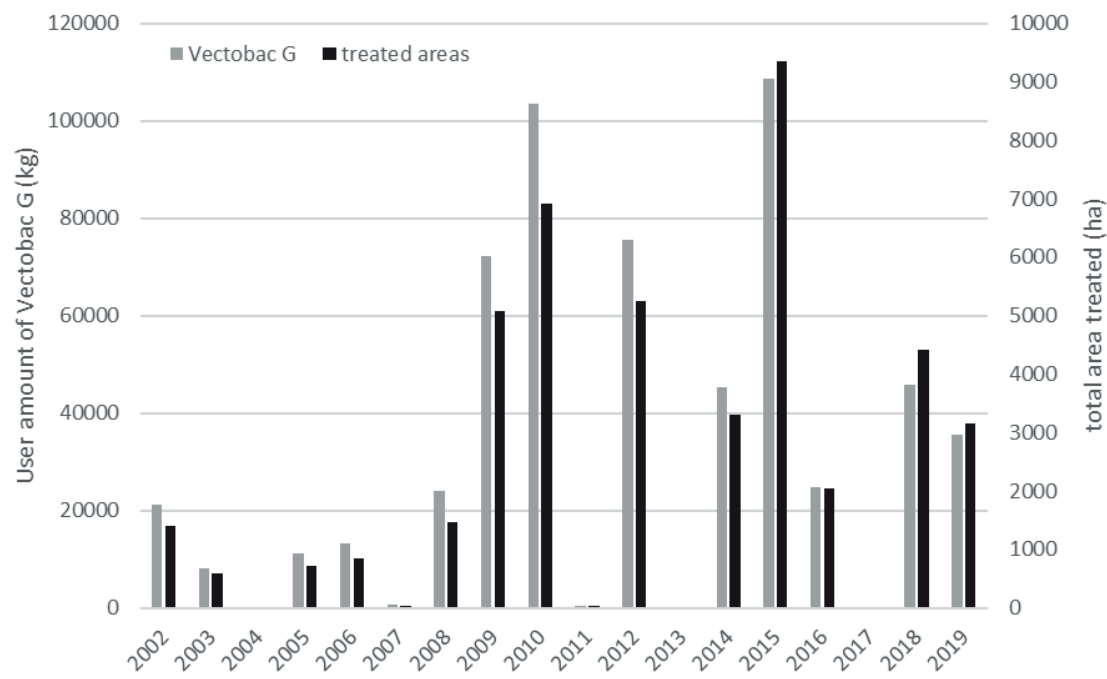

Figure 3. The amount of VectoBac G applied by helicopter in the River Dalälven floodplains for mosquito control and the total area treated per year for the years 2002 to 2019.

The GPS-points are transferred to a GIS-software and plotted on the DEM. The lakes in the floodplain are situated at different elevations, and the inundated areas are therefore modelled for each sub-area. As floodwater mosquito larvae are rare or absent in open deep water, the DEM is used to exclude those areas from treatments. The water depth limit for application depends on vegetation density and height as vegetation provides retreats for mosquito larvae in open waters. During spring floods, when there is little and low vegetation, areas up to $40 \mathrm{~cm}$ water depth are included in the applications, while during summer with plenty of vegetation, the limit is set at 60 $\mathrm{cm}$ water depth. In the GIS, the relevant areas are defined and prepared as polygons for the helicopter treatments.

Application of VectoBac $\mathrm{G}$ by helicopter can start approximately two to three days after detecting the first floodwater mosquito larvae, including the time needed to collect and analyse all necessary technical and biological information. Two sling buckets with rotating discs are calibrated for application of VectoBac $G \AA$. Using two buckets makes application very efficient, allowing for simple change of bucket for the helicopter pilot without landing (Fig. 4). 
In the helicopter, a navigation system connected to a GPS with a high updatefrequency reads the polygons as areas to be treated. The pilot prepares the appropriate flight routes with a defined distance $(20-30 \mathrm{~m}$, exact distance is based on calibration results) between flight lines, guiding flight routes ensure complete coverage within each treatment area. All the VectoBac $\mathrm{G}^{\circledR}$-applications are logged and transferred to the GIS for assessing the areas covered.

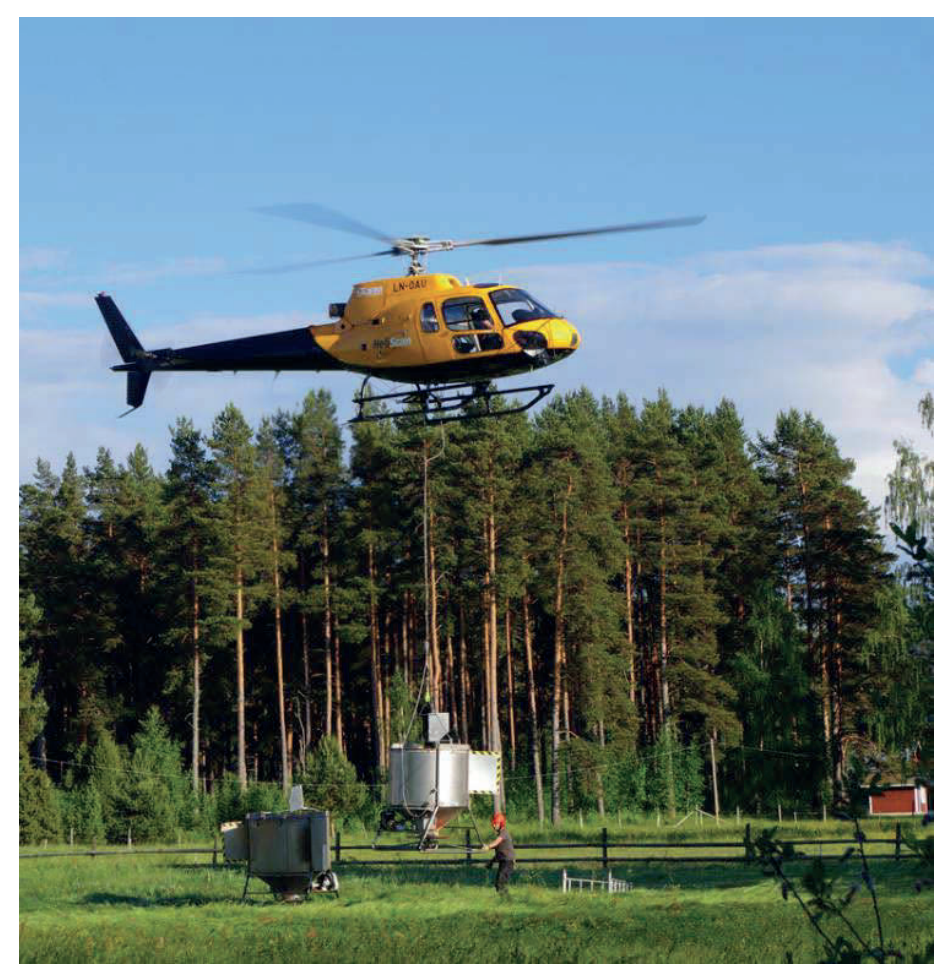

Figure 4. The use of two sling buckets, combined with change of bucket without landing the helicopter, allows for increased speed and reduced cost for aerial application of VectoBac $G$ in the River Dalälven floodplains, central Sweden (credit J. O. Lundström).

All Bti-treatments should be completed before the mosquito larvae reach fourth instar. Therefore, especially during warm summer weeks, large floods require very rapid and efficient operations. Fortunately, there is almost 24 hours of daylight during summer in this part of Sweden. If necessary, the helicopter can apply VectoBac $G \AA$ from approximately 04:00 in the morning until 24:00 at night. These intensive $20 \mathrm{hrs}$ working days require double crew on duty both on the ground and in the air.

In May 2018, a total area of 4411 ha was treated, including areas in seven municipalities along an approximately $100 \mathrm{~km}$ stretch of the River Dalälven, the largest mosquito control operation so far. Treatments were completed in 5 days with successful reduction of floodwater mosquito larvae. Currently, more than 1100 ha of natural wetlands can be treated by helicopter per day. 


\subsection{Eighteen Years of Bti-based Ae. sticticus Control}

The goal for the floodwater mosquito control is to reduce mosquito abundance to less than 500 mosquitoes per trap-night to ensure that people in the River Dalälven floodplains can live normal lives during the short summer in Sweden. As mentioned, mosquito abundance in the area was extremely high before initiation of control and people were plagued by blood-seeking Ae. sticticus females, even in the centre of towns in the middle of the day. For example, in the centre of Österfärnebo village we measured 23000 mosquitoes per CDC trap-night in August 2000 (Fig. 5). This measurement was before the first VectoBac $G^{\circledR}$ application.

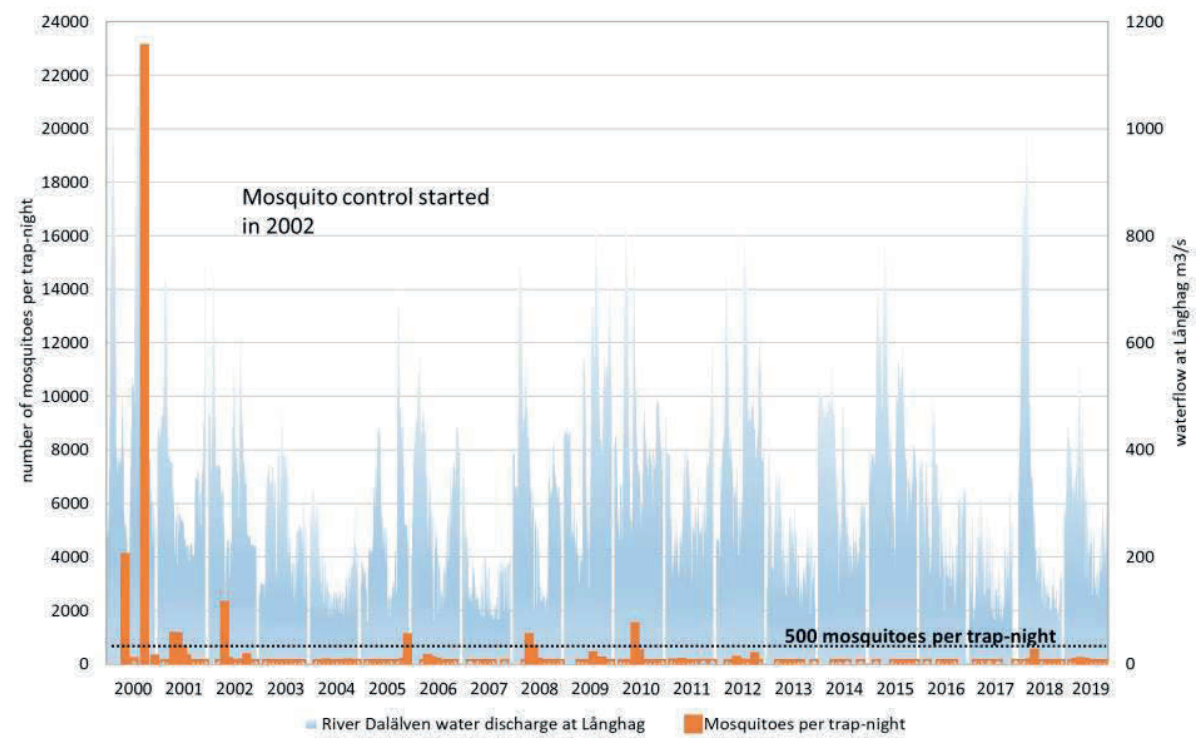

Figure 5. The number of mosquitoes per trap night in central Österfärnebo and River Dalälven water discharge at an upstream station from 2000 to 2019. The goal of mosquito control is to reduce mosquito abundance to less than 500 mosquitoes per trap night (reproduced with permission from Biologisk Myggkontroll 2019).

Since the start of mosquito control in 2002, mosquito abundance has been significantly reduced and since 2013, the number of mosquitoes collected in the trap in central Österfärnebo has been kept below 500 individuals per trap-night. This shows the effectiveness of successful Bti-applications and the results are greatly appreciated by both the local people and the visitors.

\section{PREVIOUSLY SUGGESTED ALTERNATIVE CONTROL METHODS}

Swedish authorities, including the Swedish Environmental Protection Agency (Swedish EPA), realize the importance of floodwater mosquito control and the need for Bti-treatments, but nevertheless want to reduce the usage of VectoBac $G \AA$ in 
favour of alternative methods. However, the enormous abundance of mosquitoes causing the nuisance makes this a quite complicated task, since a very dramatic reduction is needed to reach the less than 500 mosquitoes per trap-night required by the locals and visitors alike.

For example, in Österfärnebo village a $97.8 \%$ reduction was required to reduce the 23000 mosquitoes per trap-night to the acceptable abundance of 500 mosquitoes per trap-night. With respect to the impressive flight range of blood-seeking Ae. sticticus females, this means in practical terms that at least $90 \%$ of the Ae. sticticus larvae in at least $95 \%$ of the shallow flooded areas within $5 \mathrm{~km}$ around the village need to be controlled (Schäfer and Lundström 2014).

The alternative methods specifically suggested by the Swedish authorities are 1) changing the hydrology of the River Dalälven, and 2) increasing the mowing and grazing in the wet meadows (Lundqvist et al. 2013).

\subsection{Changing the Hydrology of the River Dalälven}

Changing hydrology for floodwater mosquito control requires stabilizing the water level to avoid floods and such a hydrological regime can cause a very strong reduction in mosquito abundance if fully implemented. However, nature conservationists request increased flood magnitude and duration in May and June, which is also the major larval production period for Ae. sticticus. Clearly, a single hydrological strategy will not be able to achieve the requirements for both a stable water level and increased flooding. In addition, this topic involves a very large number of stakeholders and many laws and regulations that control the water flow and water levels in different parts of the river. Furthermore, implementing the whole process would be very costly and time-consuming. Thus, reducing flood-water mosquito nuisance by hydrological changes of the River Dalälven, without reducing biological diversity, is a highly complex task that could be considered almost impossible (Hedström-Ringvall et al. 2017).

\subsection{Increased Mowing and Grazing in the Wet Meadows}

The suggestion of using mowing and grazing as alternative mosquito control methods originates from the general opinion that mosquito nuisance was less severe more than a century ago, when mowing and grazing of the floodplain meadows were common.

One study could show fewer mosquito larvae in areas with mowing and grazing than in areas without these methods, but this study was restricted to one year (Östman et al. 2015). In an unpublished study comparing the numbers of eggs in areas with and without mowing, no difference was found, and thus no long-term effect of mowing or grazing on the abundance of floodwater mosquitoes can be expected (Östman 2013).

We obtained similar results when comparing our own larval surveillance data over 15 years from areas with and without mowing and grazing Thus, although mowing and grazing sometimes might result in lower abundances of floodwater mosquito larvae, these measures cannot serve as reliable mosquito control methods. The potential reduction of larval abundance is too low and too unpredictable. 
The search for effective alternatives to control Ae. sticticus in the River Dalälven floodplains should identify methods that could fulfil three main criteria: 1) ability to obtain very strong population suppression, 2) being environmentally neutral, and 3) suitable for large-scale application in natural swamps, marshes and wet meadows.

Evidently there are few mosquito control methods, other than larviciding with Btibased products, capable of inducing such a strong population reduction without adding substances that might represent a distinct risk to the environment. In addition, Sweden is a member of the European Union and should comply with the biocide directive (EU 2012).

\section{NEW METHODS FOR MOSQUITO CONTROL}

Several potential new mosquito population suppression methods have surfaced in the last decades including the Sterile Insect Technique (SIT), the Incompatible Insect Technique (IIT), the Release of Insects carrying Dominant Lethality (RIDL), and genetically modifications based on CRISPR-Cas9 technology (Huang et al. 2017). The RIDL and CRISPR-Cas9 technologies have potential for strong population suppression, but the genetic modifications forming the strategic base for the methods will probably induce very strong counter-reactions from the general public, the Swedish EPA and other environmental protection authorities.

The SIT is a species-specific and environmentally safe method for area-wide management of insect pests which relies on repeated release of a large number of sterile male insects (Knipling 1955, 1979, 1998; Krafsur 1998; Dyck et al. 2021). The population reduction effect is achieved after sterile males are released and mate with the wild females, which will then lay infertile eggs. If a surplus of sterile males is regularly released on an area-wide basis over a sufficient time period, and they successfully mate with the local females, ultimately this will result in suppression or local elimination of the target insect population. The necessary ratio of released sterile males to local fertile males depends on the biology of the target species, the initial wild population density, the risk of reinfestation from neighbouring areas, the competitiveness of the released sterile males, and the complementary control operations that can be performed (Dame et al. 2009). The SIT has and is being used in successful area-wide integrated pest management programmes (AW-IPM) against the New World screwworm fly Cochliomya hominivorax (Coquerel), the Mediterranean fruit fly Ceratitis capitata (Wiedemann) and other tephritid flies, tsetse flies, the codling moth Cydia pomonella (L.), the false codling moth Thaumatotibia leucotreta (Meyrick) and the pink bollworm Pectinophora gossypiella (Saunders) (Lindquist et al. 1992; Vreysen et al. 2007; Dyck et al. 2021; Boersma, this volume; Nelson, this volume; Staten and Walters, this volume).

SIT field trials in the 1970's and 1980's demonstrated that it could also work against mosquitoes (Patterson et al. 1970; Lofgren et al. 1974; Benedict and Robinson 2003; Dame et al. 2009). In the last decade, the Joint FAO/IAEA Programme has been the main driver for development of the mosquito SIT package (Lees et al. 2014; Bourtzis et al. 2016). The focus is on three mosquito vector species of major medical importance: the arbovirus vectors Aedes aegypti L. and Aedes albopictus (Skuse), and the malaria vector Anopheles arabiensis Patton. 
Major technical improvements for the SIT against the two Aedes species have already resulted in successful SIT pilot-scale field studies, paving the way for the development of the SIT as a full-scale mosquito population suppression method (Lees et al. 2021). Successful field trials of the SIT for suppressing populations of Aedes mosquitoes are recorded for Ae. albopictus in Italy (Bellini et al. 2013), while a SIT/IIT combination was shown successful in suppressing a population of $A e$. albopictus in China (Zhang et al. 2016; Zheng et al. 2019) and suppressing a population of Ae. aegypti in Thailand (Kittayapong et al. 2019).

The IIT relies on symbiotic bacteria of the genera Wolbachia, inherited in insects, and that can manipulate the reproductive system of their host insects (Kittayapong et al. 2002; Werren et al. 2008). The incompatibility of sperm from a Wolbachiainfected male that fertilizes the eggs of a non-infected female, or of a female that is infected with another Wolbachia strain, can be used for population suppression by the IIT. The technique was first developed in 1967 against the lymphatic filariasis vector Culex pipiens fatigans in Burma, and the IIT was shown capable of eliminating the local mosquito vector population (Laven 1967). More recent positive results have been obtained in field experiments with the IIT against Aedes polynesiensis Marks 1954, Culex pipiens quinquefasciatus Say 1823, Ae. albopictus and Ae. aegypti (Atyame et al. 2011, 2015; Moretti and Calvitti 2012; O'Connor et al. 2012; Ritchie et al. 2015; Mains et al. 2016; Strugarek et al. 2019).

The control action of both the SIT and the IIT relies on providing a surplus of sexually active males that upon mating with the local females cause infertility of their eggs. These eggs cannot hatch to larvae, thus precluding development of new mosquito generations and over time the local population declines and perhaps, if isolated, is even locally eliminated. With the SIT, this is achieved by the release of sexually active mosquito males that have been sterilized by radiation. With the IIT, infertile eggs are the consequence of incompatibility between released sexually active Wolbachia-transfected males mating with local females that either are uninfected by Wolbachia or are infected with a different Wolbachia-strain.

We consider the SIT and the IIT as interesting to evaluate as part of an integrated approach for area-wide population suppression of our target species, the floodwater mosquito Ae. sticticus. Being environmentally neutral, both the SIT and the IIT could, after population pre-treatment with VectoBac G, potentially meet the criteria of inducing a high level of population suppression, although they have not been tested against a floodwater mosquito species.

\section{PREREQUISITES FOR A STERILE MALE STRATEGY TO CONTROL Aedes sticticus}

Applying the SIT or the IIT for Ae. sticticus control requires a laboratory colony of the species, a facility for mass-rearing of mosquitoes, the sterilisation of males, a transport strategy, a dispersal system, monitoring systems for several life stages, and a method capable of reducing the population of this superabundant species before commencing the sterile male release.

Differences in ecology and behaviour will demand a partially different SIT strategy for Ae. sticticus than for more commonly considered species Ae. aegypti or 
Ae. albopictus (Lees et al. 2021). The latter two have continuous reproduction during a major part of the year and larval habitats are small, cryptic and widely dispersed. SIT-based control of these species requires that sterile males are released at least once a week over many months over mosquito habitat in domestic and rural areas. In contrast, Ae. sticticus larval sites are well-defined temporary flooded areas with synchronised batches of larvae during a flood event. Thus, SIT-based control requires very focused release of males in conjunction with flood events. The synchronised emergence of Ae. sticticus in relation to floods indicate that the release of sterile males during this emergence period could be sufficient to induce a high percentage of egg infertility in local females. However, it is probably a safer strategy to continue with weekly releases of sterile males for an additional 3-4 weeks after each emergence.

Several supporting factors necessary for successful SIT or IIT application are already well established for Ae. sticticus, while other factors need to be dealt with. As shown on previous pages, an efficient method for large-scale larval suppression is available that can significantly reduce population size before sterile male release. One factor in favour of implementing the SIT or the IIT against Ae. sticticus is that mating occurs in or near well-defined larval breeding areas with specific relation to flood events. Another factor in favour of the SIT or the IIT is the availability of existing methods to measure gender, larvae and egg abundance. The following pages provide details on the major factors that need to be addressed to develop and test the SIT or the IIT against Ae. sticticus in Sweden.

\subsection{Egg Storage and Hatching}

The eggs of the floodwater mosquito Ae. sticticus range from 0.610 to $0.645 \mathrm{~mm}$ in length and from 0.180 to $0.215 \mathrm{~mm}$ in width (Gjullin et al. 1950). The eggs are extremely hardy and remain viable for several years (Gjullin et al. 1950; Trpis and Horsfall 1967), allowing for a long shelf-life and stockpiling of eggs during industrial mass-production year-round. Eggs could be stored at $4{ }^{\circ} \mathrm{C}$ for long time periods.

The eggs will not hatch in clean tap water but hatch readily in a willow-leaf infusion or when amino acids are added to the water (Gjullin et al. 1950). A reduction in dissolved oxygen is the main hatching stimulus for the eggs (Gjullin et al. 1950) with increased eclosion when the hatching media is a nutrient rich broth (Trpis and Horsfall 1967). Hatching of eggs can occur at $8^{\circ} \mathrm{C}$, but the hatching is more efficient and better synchronised at higher temperatures with optimum of about $21^{\circ} \mathrm{C}$ (Trpis and Horsfall 1967). Eggs of Ae. sticticus may have to be exposed to a period of winter before hatching (Horsfall and Trpis 1967).

\subsection{Larval Rearing}

The development of Ae. sticticus larvae depends on temperature, diet, larval density and water depth (Trpis and Horsfall 1969). Water temperatures of $8^{\circ} \mathrm{C}$ to $32^{\circ} \mathrm{C}$ were tested, and $21^{\circ} \mathrm{C}$ was considered the optimum rearing temperature with maximum percentage maturing in the shortest time interval. At $25^{\circ} \mathrm{C}$ larval development was accelerated by 1-2 days, but mortality increased. 
The larvae were fed liver yeast suspended in water, and for a pan with 30 larvae in $1700 \mathrm{ml}$ of water the optimal yield was achieved when the larvae were provided $110 \mathrm{mg}$ of dry yeast equivalent per pan per day. Feeding every second day required doubled amount of food and feeding every third days resulted in increased mortality. The density of larvae, reared in $1700 \mathrm{ml}$ of water at $25^{\circ} \mathrm{C}$, influenced the developmental time. Pupation began and was completed on day 6 in pans with 30 larvae, while pupation occurred days 7 to 10 in pans with 60 larvae and on days 8 to 13 in pans with 90 larvae. Water depth was also important, especially at higher temperature both development and survival were best in very shallow water.

\subsection{Adult Rearing and Mating}

The rearing of adult Ae. sticticus may require relatively large cages of $1.0 \times 2.0$ x 2.5 $\mathrm{m}\left(5 \mathrm{~m}^{3}\right)$ to maintain a normal mating behaviour of the laboratory reared males. Mating of Ae. sticticus occurs in damp and shady areas among trees and bushes, but they are not forming any obvious swarms. The actual triggers of mating activity are unknown, and this is of course a potential obstacle when trying to establish a laboratory colony. Experience from colonization of other mosquito species showed that a combination of natural light cycle and a sufficiently sizeable cage triggered mating (Kuhn 2002; Lundström et al. 1990). Small cage size can induce a problem if mating couples split when not in the air, but this is not a problem with Ae. sticticus.

Photo documentation of a mating Ae. sticticus couple in the field show that they continue the sexual activity even after landing on the rubber boot of the observer (Fig. 6).

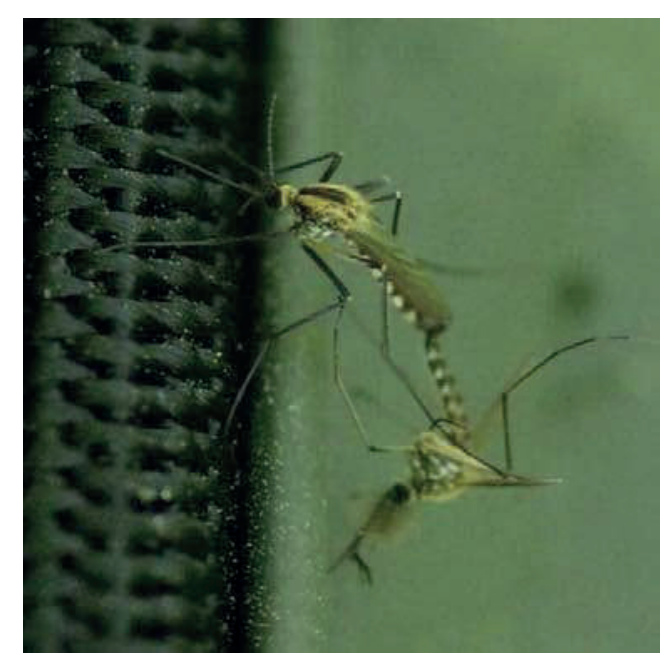

Figure 6. A mating couple of the floodwater mosquito Aedes sticticus, that initiated mating in the air and continued after they landed on the photographer's rubber boot, in the Valmbäcken alder swamp in July 2015 (credit J. O. Lundström). 
Our strategy for colonization of Ae. sticticus will initially focus on evaluating the mating in relatively large cages with simulated natural dusk and dawn periods. If not successful, forced copulation could be used for a few generations. Experience from colonization of the floodwater mosquito Ae. vexans could provide additional suggestions (Kuhn 2002). The colonization of Ae. vexans was based on mosquitoes released in a walk-in cage of $5 \mathrm{~m}^{3}$ and simulated dusk and dawn periods. Once the colony was established, Ae. vexans adapted to mating in smaller cages with a $1.4 \mathrm{~m}^{3}$ volume. However, such changes in behaviour could be a disadvantage for the laboratory reared males in the competition for mating with wild females. We are also aware that the close ecological similarities between these two floodwater Aedes species of the northern hemisphere is no guarantee that colonization of Ae. sticticus will be successful.

The adult mosquitoes require a food regime with constant access to $10 \%$ sugar solution (males and females) while the females in addition need to be provided blood approximately once a week for egg production. Our practical experience is that Swedish Ae. sticticus readily feed on bovine blood heated to $38^{\circ} \mathrm{C}$ and provided from a membrane feeder. The initial unsuccessful trials to colonize Ae. sticticus have shown that there is no need for a specific egg substrate, since the females readily deposit the eggs on moist paper. However, many details concerning larval and adult rearing and mating will have to be optimized before efficient rearing and mass-production of highquality males will be possible.

\subsection{Sex Separation}

The male pupae of Ae. sticticus are smaller than the female pupae, allowing for mechanical size-based sex separation in the pupal stage. The Fay-Morlan separator, a mechanical sex separation method (Fay and Morlan 1959; Sharma et al. 1972; Focks 1980), is the standard method for sex separation of Ae. aegypti and Ae. albopictus pupae. The sieves method to separate male and female pupae is also commonly used and both methods are potential options for Ae. sticticus sex separation.

The eventual contamination with some female mosquitoes among the sterile mosquito males, is a serious problem. The blood-seeking females could cause nuisance, which may cause public aversion that severely reduces the perceived effect of the control strategy. In addition, females mixed with the released sterile males could also divert some mating away from the target native females, thereby reducing the effect of the SIT intervention. Therefore, an efficient and secure method of separating males from females in the mass-production process is imperative to the success of the strategy.

\subsection{Sterilisation by Ionizing Radiation}

Sterilisation of male insects for the SIT can be done by ionizing radiation or by chemical treatment (Bakri et al. 2021). Sterilisation by ionizing radiation that randomly destroys fractions of DNA in the male gonads was the first tested method. Sterilisation by $\mathrm{X}$-ray or gamma radiation from a ${ }^{60} \mathrm{Co}$ radiation chamber is nowadays 
the standard method of sterilizing male insects for SIT application. This is an extremely reliable method, suitable for industrial-scale insect sterilisation.

The use of gamma radiation for sterilisation of mosquitoes was first tested against Ae. albopictus in Italy (Bellini et al. 2013) and has later been more generally applied as the mosquito sterilisation method. However, the use of ${ }^{60} \mathrm{Co}$ requires special security measures, adequate regulation in the country, radiation protection protocols, and the initial investment is high. More recently, X-ray machines suitable for masssterilisation of male insects have been developed and are becoming available (Yamada et al. 2014; Bakri et al. 2021). The X-ray equipment is cheaper, requires no regulation in the country, and requires less security than the gamma radiation equipment. Also, X-ray is commonly used for medical purposes making it probably the least controversial method for sterilizing male Ae. sticticus.

\subsection{Wolbachia and Aedes sticticus}

The Wolbachia bacterial symbiont can be used to induce sterility through mating incompatibility (Bourtzis 2008; Werren et al. 2008; Rasić et al. 2014). Recently, the United States Environmental Protection Agency (US-EPA) has approved the release of Wolbachia pipientis transfected male Ae. albopictus (wPip strain; ZAP males) for population suppression in the District of Columbia, and in 20 states of the USA (USEPA 2017; Waltz 2017).

The use of Wolbachia for IIT implementation is dependent on knowledge about the eventual occurrence of natural infection in the target populations, as it requires that the wild female is either free of any Wolbachia bacteria symbionts or carries another strain of the bacteria than the infected and released males.

A preliminary study of the occurrence of Wolbachia was carried out with Ae. sticticus samples collected during the regular annual mosquito surveillance programme in the River Dalälven floodplains by Biologisk Myggkontroll (Schäfer et al. 2018). Wolbachia-specific PCR screening, as reported in Kittayapong et al. (2000), was carried out in 279 mosquitoes of 17 mosquito species for naturally occurring infections with this bacterial symbiont (Table 1). A total of 7 out of 17 species $(41.2 \%)$ contained the Wolbachia symbiont. However, the PCR results indicated that the 20 Ae. sticticus individuals screened were free of the Wolbachia symbiont, indicating that the species is probably free from Wolbachia infection.

Based on this information, there is potential for using Wolbachia-transfected Ae. sticticus males for population suppression. This would require the establishment of a Wolbachia-transfected Ae. sticticus strain that could be produced in large numbers for male-only release. The use of a local mosquito strain as well as a local Wolbachia strain might also make it easier to receive the necessary permits from the authorities.

\subsection{Transport}

The production of sterile male Ae. sticticus could either be done in Sweden, or in another country within reach for timely delivery to the suggested pilot study area in the River Dalälven floodplain. Any decision on the location of such a production unit will require an evaluation of the costs and reliability for production and delivery, as 
well as the logistics for delivery, in relation to the reaction time from low-level maintenance production to full-scale production for release. Also, it has to be guaranteed that the long-distance shipment is not detrimental to the quality of the insects. A key factor is the availability of a provider with the knowledge and drive to perform the sterile male production.

Table 1. The occurrence of the bacterial symbiont Wolbachia in mosquito species collected in the wetlands of the River Dalälven floodplains, central Sweden

\begin{tabular}{|c|c|c|c|}
\hline Species & No. Tested & $\begin{array}{c}\text { No. Wolbachia positive } \\
\text { specimen }\end{array}$ & $\begin{array}{l}\text { Percent } \\
\text { positive }\end{array}$ \\
\hline Aedes annulipes (Meigen) & 32 & 0 & 0 \\
\hline Aedes cantans (Meigen) & 15 & 0 & 0 \\
\hline Aedes cinereus (Meigen) & 30 & 5 & 16.67 \\
\hline Aedes communis (De Geer) & 20 & 0 & 0 \\
\hline Aedes diantaeus (Howard, Dyar \& Knab) & 19 & 0 & 0 \\
\hline Aedes intrudens (Dyar) & 18 & 0 & 0 \\
\hline Aedes punctor (Kirby) & 20 & 0 & 0 \\
\hline Aedes sticticus (Meigen) & 20 & 0 & 0 \\
\hline Aedes vexans (Meigen) & 20 & 0 & 0 \\
\hline Culiseta alaskensis Ludlow & 13 & 0 & 0 \\
\hline Culiseta bergrothi Edwards & 15 & 8 & 53.33 \\
\hline Culiseta morsitans (Theobald) & 5 & 4 & 80.00 \\
\hline Culiseta ochroptera (Peus) & 2 & 0 & 0 \\
\hline Culex pipiens L./ torrentium Martini & 4 & 4 & 100.00 \\
\hline Coquillettidia richiardii Ficalbi & 10 & 10 & 100.00 \\
\hline Anopheles maculipennis sl (Meigen) & 22 & 9 & 40.91 \\
\hline Anopheles claviger (Meigen) & 14 & 6 & 42.86 \\
\hline
\end{tabular}

A recent SIT pilot study in Heidelberg, Germany, relied on sterile male Ae. albopictus produced in Italy and the transport time from the production unit to field release was $24 \mathrm{~h}$ by car (R. Bellini, personal communication). More recently, this sterile male transport is done by DHL delivery by air, shortening transport time and increasing reliability. Transport by air allows rapid long-distance transport between mosquito factory and the field release area.

Insects are poikilotherms and thus have about the same body temperature as their surrounding environment. This is reflected in slower activity at low temperature and increasing activity with rising temperature within certain temperature limits. Thus, it is possible to chill mosquitoes and thereby make them less active and less vulnerable to physical damage during transport. Since the chilling reduces all life processes, it allows for packing of very large number of insects in a small volume as long as they are in a chilled state. 
The technique of chilling mosquitoes for long-distance transport has been tested for Anopheles arabiensis, Ae. aegypti and Ae. albopictus and the conclusion is that there is large variability in responses (Culbert et al. 2017, 2019). Apparently, the reaction to chilling needs to be established for each species and may even have to be evaluated for the specific population (Culbert et al. 2019). Although the northern floodwater mosquito Ae. sticticus is already used to an environment where immobilization by chilling is inevitable, there is an obvious need to test the species for optimal transportation temperature before practical use.

\subsection{Male Mating Quality}

Since mating success is central for the SIT and the IIT, there is a need to evaluate male mating quality on a regular basis. This is normally done using walk-in field cages to sufficiently frequently test for mating competition and success. This argues in the direction of creating large and efficient production units, supplemented with capacity for adequate male quality evaluation. Such facilities need capacity for timely delivery of quality sterile males for release.

\subsection{Male Dispersal}

Ground release of Ae. sticticus males in large and inaccessible natural wetland areas is not possible within a limited timeframe. Aerial release is the main alternative as it is rapid and allows high precision; it is also the least disturbing for vegetation and animals alike. The release should preferable be done by either helicopter or drone (unmanned aerial vehicle, see Benavente et al., this volume), but probably not by airplane, as the male mosquitoes are fragile and may become damaged if speed of the dispersing aircraft is too high.

The dispersal of Ae. sticticus males, in conjunction with mating, is important information when deciding on the male release strategy. Our preliminary observations provide evidence of Ae. sticticus mating in the same general area as the larval habitat. The synchronised hatching of Ae. sticticus eggs during a flood, the likewise synchronised development of larvae to pupal stage, and the emergence of males about one day before females provide opportunities for males to encounter emerging females without searching over extensive areas. Furthermore, the temporary flooded areas are very humid and thereby favourable environment for mosquitoes that are sensitive to desiccation.

Mating of Ae. sticticus was only observed in the shade under deciduous trees and bushes. The present level of biology knowledge indicates that the mating in this species occurs in the shaded terrestrial parts of the temporary flooded wet meadows and swamps. This information indicates that it is possible to develop a remote assessment method for locating actual mating areas. Release of sterile Ae. sticticus males could be concentrated in the defined mating environment and thus optimize impact in relation to time and costs. 


\subsection{Monitoring of Ae. sticticus Males and Females}

The ability of released Ae. sticticus males to survive and disperse in the target areas, and the actual abundance of sterile males relative to native fertile males, are crucial to follow before, during and after the release. Discrimination of released sterile males from native males of the same species will require a marking system for released males, for example fluorescent powder or dye (Pal 1947; Verhulst et al. 2013). However, marking with fluorescent dye is not always recommended for mosquitoes as a coloured mosquito might have negative impact on the human population acceptance of the technique. Johnson et al. (2017) evaluated a new internal marking technique for mosquitoes using rhodamine B, showing that the marking remained after sugar-feeding and was visible for lifetime in Ae. aegypti. However, the authors recommend that small-scale mark-release-recapture experiments be performed to obtain more accurate estimates of male survival and mark persistence prior to adoption as an operational assessment (FAO/IAEA 2019).

Mosquito males are more difficult to collect than the females, and there is no trapping system available for specific sampling of Ae. sticticus males. As no obvious way of attracting and sampling males is available, we decided to test a more general strategy using the MosVac, a portable battery-operated, aspirator (Go Green Co., Ltd., Bangkok, Thailand).

The test was done in the Valmbäcken alder swamp, at the edge of the frequently flooded lake Färnebofjärden and in conjunction with a flood event, to make sure that males would occur in the study area. The test was carried out in June 2015, on the day we expected emergence of adult Ae. sticticus to commence. Only males were caught during the first sampling event, while on the following consecutive sampling days a mixture of males and females were collected (Fig. 7).

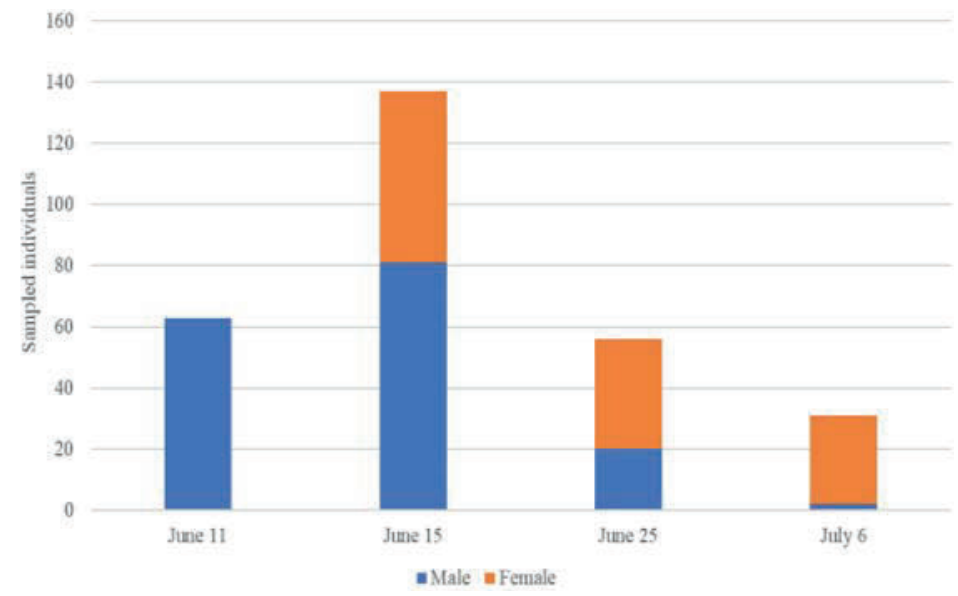

Figure 7. Abundance of male and female Aedes sticticus measured by vacuuming grassy and bushy areas of the Valmbäcken alder swamp, River Dalälven floodplains, with a MosVac aspirator. The first sampling was done June 11, 2015, coinciding with the first day (D1) of adult emergence after the flood in May. Sampling was repeated June 15 (D5), June 25 (D15) and July 6 (D26). 
Only a few male Ae. sticticus were collected 26 days after initiation of emergence, when the male to female ratio was heavily distorted towards female dominance in the sample.

These preliminary data show that the MosVac aspirator was able to sample sufficient numbers of males for evaluating a pilot SIT study against Ae. sticticus. It also indicated that male abundance was reduced more rapidly than female abundance, with almost no males left approximately four weeks after adult emergence. Our intention is to carry out more detailed evaluations of male Ae. sticticus sampling strategy using MosVac aspirators, and other potential male sampling methods, to develop a standardized protocol for evaluation of sterile male releases.

Monitoring of female mosquito abundance is routinely done by Biologisk Myggkontroll (2019) in about 40 trap sites spread over the whole floodplain of the River Dalälven. Sampling is performed in all trap sites for one night every second week from spring to fall using CDC-traps baited with carbon dioxide as an attractant. This sampling will provide information on the relative abundance of the bloodseeking Ae. sticticus females that cause the nuisance.

\subsection{Measuring the Abundance of Ae. sticticus Larvae During Floods}

The Ae. sticticus larval abundance is routinely measured by dipping with a white plastic dipper on a long shaft. A large amount of data on larval abundance before and after each mosquito control operation in the River Dalälven floodplains are available since 2002. Such background data are very useful when evaluating the effect of the SIT on an Ae. sticticus population, because a subsequent reduction of larval abundance is expected if sufficient numbers of native females have mated with sterile males, resulting in infertile eggs.

Furthermore, as the egg bank of Ae. sticticus remains viable for many years (Gjullin et al. 1950), it will be useful for a SIT- or IIT-based intervention to continue measuring the larval abundance as a proxy for the abundance of fertile eggs. Declining abundance of larvae over the years will show a real population reduction. This will make it possible to observe if the actual population is reduced or even locally eliminated.

\subsection{Potential IPM Strategy: Combination of Other Tools}

The high population density of Ae. sticticus in the River Dalälven floodplains, without efficient control, is of a magnitude that would make it extremely costly and almost impossible to solely rely on SIT- or IIT-based control. However, the area-wide use of aerial dispersal of VectoBac $\mathrm{G}$ against the larvae is highly efficient and already induces about a 95\%-99\% reduction in blood-seeking female abundance (Schäfer and Lundström 2014). Such pre-treatment of the pilot area, reducing the target species population to a fraction, will make it possible to decrease the required number of sterile males to be released substantially, thereby boosting both the economics of the releases and their population suppression effect. 


\subsection{A Suggested Pilot Study of SIT or IIT Application Against Aedes sticticus}

Before implementing new area-wide population suppression methods against Ae. sticticus, there is an obvious need for a pilot study of the techniques to be integrated against the target population in its natural setting. The results of the pilot study will provide guidance for evaluating efficacy and will also provide guidance on whether and how to proceed when expanding into AW-IPM programmes using the SIT or the IIT.

Two flood-prone and extremely productive areas for Ae. sticticus have been selected as suggested pilot study areas (Fig. 8). Former lakes Hallsjön and Karbosjön are located close to the village of Huddunge and have been subject to Bti-based mosquito control since 2005. All known floodwater mosquito breeding sites within flight distance are included in the routine Bti-treatments, thus the study areas are protected from massive reinvasion of Ae. sticticus and would function as isolated populations.

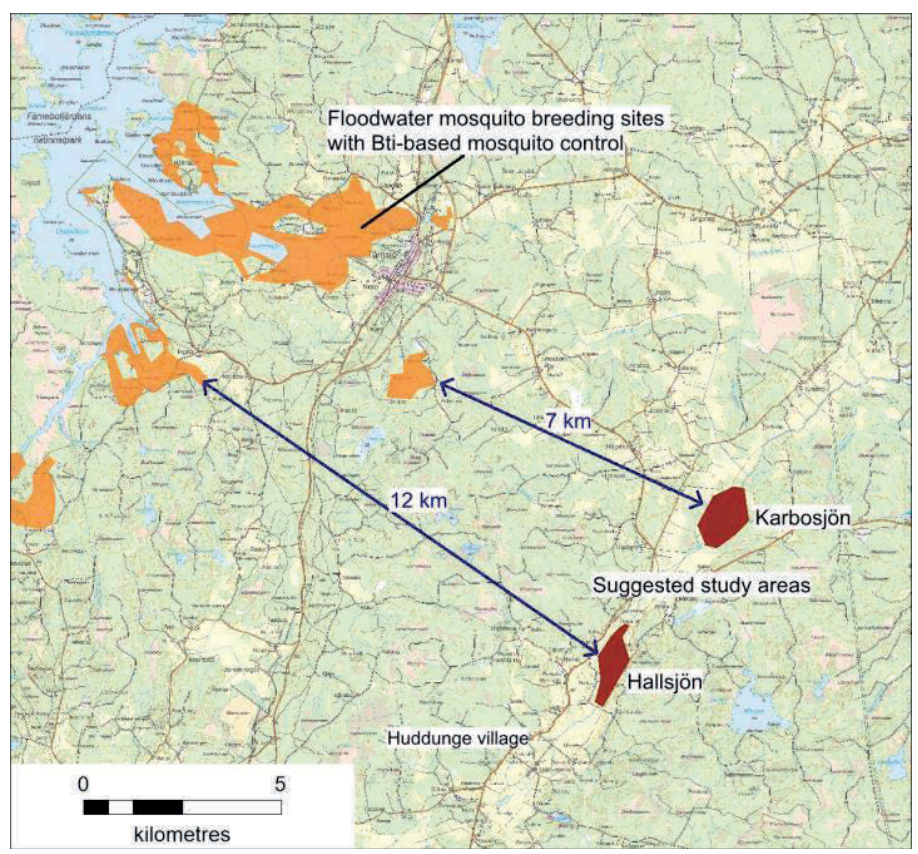

Figure 8. The two suggested areas, Hallsjön and Karbosjön for a pilot study of the SIT against the floodwater mosquito Aedes sticticus are located northeast of Huddunge village and are isolated from breeding sites close to the River Dalälven. All breeding sites are included in routine Bti-based mosquito control which protects the study areas from massive reintroduction of Ae. sticticus females. 
The enormous mosquito nuisance problems around Lake Hallsjön were the motive to initiate mosquito control using VectoBac G spread from helicopter, as previously described. A first survey of mosquito abundance in the Hallsjön area was carried out in 2004, and in 2005 mosquito control was commenced. From 2005 onwards, the abundance of female Ae. sticticus is regularly monitored with CDC-trapping once every second week from May until September each year (Fig. 9).

The relative abundance of blood-seeking Ae. sticticus females before initiation of treatments was about 16000 per CDC-trap and night. After several years of treatment with VectoBac G, the maximum number of female Ae. sticticus collected any time during summer is 11-44 per CDC-trap and night, representing a 99.97\% reduction. This proves the excellent population suppression resulting from professional VectoBac $\mathrm{G}$ larviciding and confirms the almost total elimination of Ae. sticticus larvae as observed within $24 \mathrm{~h}$ after each treatment.

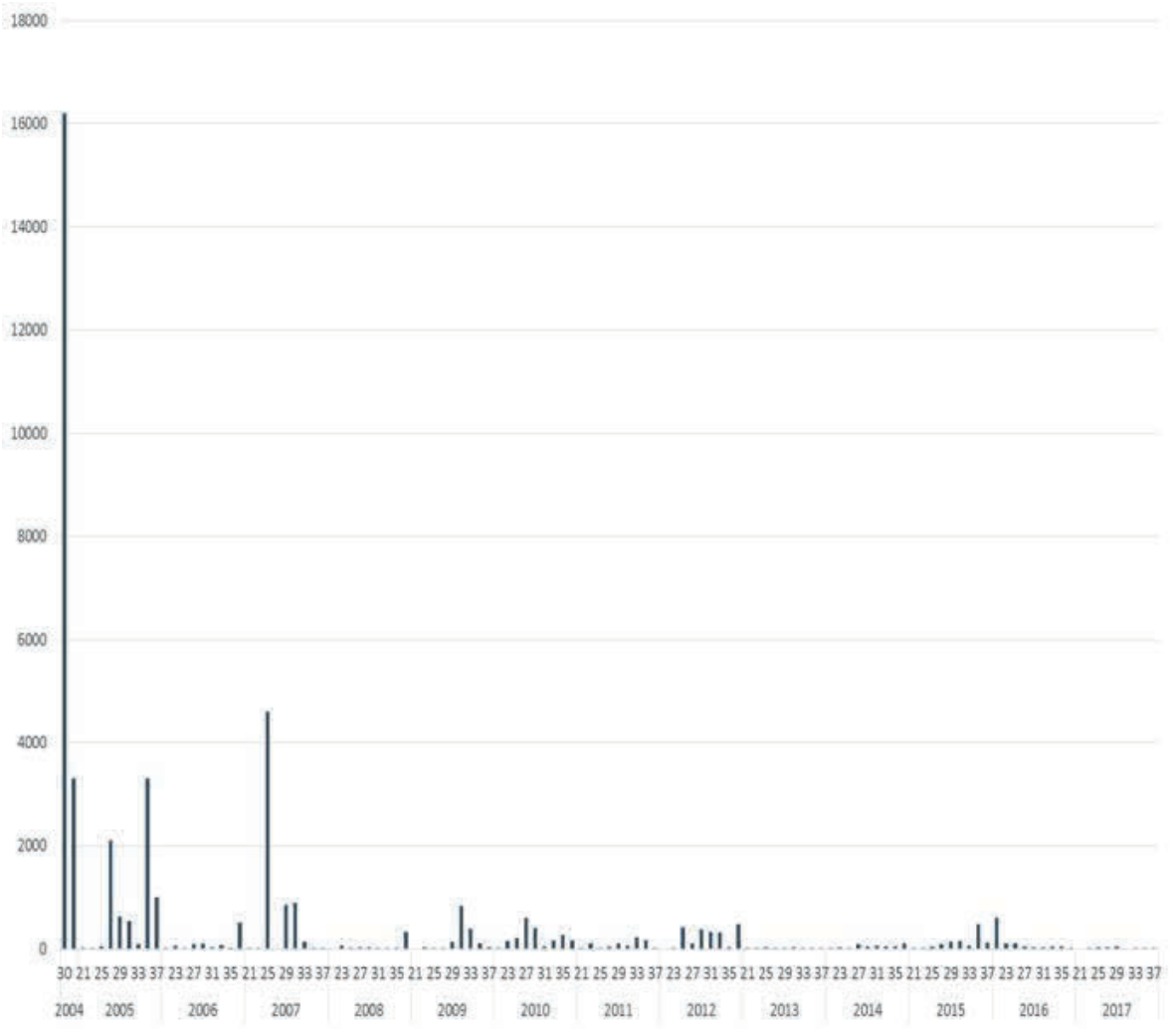

Figure 9. The abundance of blood-seeking Aedes sticticus females at Hallsjön, central Sweden, for the years 2004 to 2017 as measured by fortnightly sampling with CDC miniature light traps baited with carbon dioxide. Mosquito control using VectoBac G commenced in 2005, inducing a very strong reduction in abundance, except for week 27 in 2007 when a mistake allowed massive mosquito emergence (data not shown). 
The size of the remaining population of surviving Ae. sticticus males and females after treatment is difficult to measure since there remain so few individuals and these are dispersed. However, the CDC-traps are positioned in areas with trees and bushes attracting the females produced in a much larger surrounding area of wet meadow estimated at 1-2 ha. If we use 44 females as a $10 \%$ fraction of actual numbers produced in 2 ha, the production could be supposed to be 220 females per productive ha. As males and females emerge in approximately the same abundance, this would provide us 220 males per productive ha. The total area of the two pilot areas is about 150 ha, and during a large flood it is estimated that about $75 \%$ of the area is producing $A e$. sticticus. Thus, only 25000 local fertile males remain in the study areas after a VectoBac $\mathrm{G}$ treatment. Based on the estimated abundance of local males, there will be a need for releasing approximately 250000 sterile or incompatible males to obtain a sterile to wild male ratio of 10:1. As can be understood, these are very approximate estimates, although they probably catch the approximate general tendency.

The success of a SIT or IIT trial is crucially dependent on the release of a sufficient number of good quality sterile males to compete with the local fertile males for mating with the local females. Therefore, it might be useful to try other methods for population size estimates before the initial release of sterile or incompatible Ae. sticticus males in the two suggested pilot study areas.

\section{PERSPECTIVES}

The sterile male technique, either the SIT or the IIT, has potential to serve as an alternative solution to sole reliance on Bti-treatments against Aedes sticticus, but for an evaluation of the real potential, the suggested pilot test needs to be performed. In case of positive and encouraging results, new challenges arise.

Setting up the SIT or the IIT over the whole of the River Dalälven floodplains will require an integrated strategy with Bti-treatments for many years, thus the desired reduction of the control agent will not be achieved for quite some time. Sterile male release will have to start in defined subsets of the floodplains, for example in the easternmost lake system and then move westwards. There is also a risk that Btitreatments will have to increase in the beginning since there are untreated areas in the current control programme. Complete area-wide coverage of breeding sites will be needed to ensure low mosquito population size and low risk for reinfestation. Thus, for approximately 10-15 years there will be a need for both large-scale Bti-treatments and sterile male releases. As a result of this intensive work, the use of the suppression agent may phase out completely, although it might be wise to keep the possibility of Bti-treatments as a backup. Release of sterile males will have to continue at a maintenance level since re-establishment of Ae. sticticus might occur.

In conclusion, integrating the sterile male technique into the management of a floodwater mosquito like Ae. sticticus means intensive work effort over many years, but the goal of an environmentally neutral mosquito control, eventually without using any suppression agent, is considered achievable. Nevertheless, this will require political decisions ensuring stakeholder commitment and the economic basis for such a project. 


\section{ACKNOWLEDGEMENTS}

We would like to acknowledge the valuable comments and suggestions from two anonymous external reviewers, and the English language support provided by Christian Blue.

\section{REFERENCES}

Atyame, C. M, N. Pasteur, E. Dumas, P. Tortosa, M. Tantely, N. Pocquet, S. Licciardi, A. Bheecarry, B. Zumbo, M. Weill, and O. Duron. 2011. Cytoplasmic incompatability as a means to control Culex pipiens quinquefasciatus mosquito in the islands of the southwestern Indian Ocean. PLoS Neglected Tropical Diseases 5: e1440.

Atyame, C. M., J. Cattel, C. Lebon, O. Flores, J.-S. Dehecq, M. Weil, L. C. Gouagna, and P. Tortosa. 2015. Wolbachia-based population control strategy targetting Culex quinquefasciatus mosquitoes proves efficient under semi-field conditions. PLoS One 10(3): e01119288.

Bakri, A., K. Mehta, and D. R. Lance. 2021. Sterilizing insects with ionizing radiation, pp. 355-398. In V. A. Dyck, J. Hendrichs, and A. S. Robinson (eds.), Sterile Insect Technique - Principles and practice in Area-Wide Integrated Pest Management. Second Edition. CRC Press, Boca Raton, Florida, USA.

Becker, N. 1989. Life strategies of mosquitoes as an adaptation to their habitats. Bulletin of the Society for Vector Ecology 14: 6-25.

Becker, N. and H. W. Ludwig. 1981. Untersuchungen zur Faunistik und Ökologie der Stechmücken (Culicinae) und ihrer Pathogene im Oberrheingebiet. Mitteilungen der Deutschen Gesellschaft für allgemeine und angewandte Entomologie 2: 186-194.

Becker, N., D. Petric, M. Zgomba, C. Boase, M. Madon, C. Dahl, and A. Kaiser. 2010. Mosquitoes and their control, Second Edition. Springer Verlag, Berlin/Heidelberg, Germany. 577 pp.

Bellini, R., A. Medici, A. Puggioli, F. Balestrino, and M. Carrieri. 2013. Pilot field trials with Aedes albopictus irradiated sterile males in Italian urban areas. Journal of Medical Entomology 50: 317-325.

Benedict, M., and A. Robinson. 2003. The first release of transgenic mosquitoes: An argument for the Sterile Insect Technique. Trends in Parasitology 19: 349-355.

Biologisk Myggkontroll. 2019. Bekämpar översvämningsmyggor vid Nedre Dalälven.

Bourtzis, K. 2008. Wolbachia-based technologies for insect pest population control. Advances in Experimental Medicine and Biology 627: 104-113.

Bourtzis, K., R. S. Lees, J. Hendrichs, and M. J. B. Vreysen. 2016. More than one rabbit out of the hat: Radiation, transgenic and symbiont-based approaches for sustainable management of mosquito and tsetse fly populations. Acta Tropica 157: 115-130.

Brust, R. A. 1980. Dispersal behavior of adult Aedes sticticus and Aedes vexans (Diptera: Culicidae) in Manitoba. Canadian Entomologist 112: 31-42.

Caquet, T., M. Roucaute, P. Le Goff, and L. Lagadic. 2011. Effects of repeated field applications of two formulations of Bacillus thuringiensis var. israelensis on non-target saltmarsh invertebrates in Atlantic coastal wetlands. Ecotoxicology and Environmental Safety 74: 1122-1130.

Culbert, N. J., J. R. L. Gilles, and J. Bouyer. 2019. Investigating the impact of chilling temperature on male Aedes aegypti and Aedes albopictus survival. PLoS One 14: e0221822.

Culbert, N. J., R. S. Lees, M. J. B.Vreysen, A. C. Darby, and J. R. L. Gilles. 2017. Optimised conditions for handling and transport of male Anopheles arabiensis: Effects of low temperature, compaction, and ventilation on male quality. Entomologia Experimentalis et Applicata 164: 276-283.

Dame, D. A., C. F. Curtis, M. Q. Benedict, A. S. Robinson, and B. G. J. Knols. 2009. Historical applications of induced sterilisation in field populations of mosquitoes. Malaria Journal 8 (Suppl. 2): S2.

Dyck, V. A., J. Hendrichs, and A. S. Robinson (eds.). 2021. Sterile Insect Technique - Principles and practice in Area-Wide Integrated Pest Management. Second Edition. CRC Press, Boca Raton, Florida, USA. 1200 pp.

(EU) European Union. 2012. Regulation (EU) No 528/2012 of the European Parliament and of the Council of 22 May 2012 concerning the making available on the market and use of biocidal products. ISSN 1977. 2012. 677: 2985. 
(FAO/IAEA). Food and Agriculture Organization of the United Nations/International Atomic Energy Agency. 2019. Guidelines for Mark-Release-Recapture procedures of Aedes mosquitoes. J. Bouyer, F. Balestrino, N. Culbert, M. Gómez, D. Petric, H. Yamada, R. Argilés, and R. Bellini (eds.). Vienna, Austria. 22 pp.

Fay, R., and H. Morlan. 1959. A mechanical device for separating the developmental stages, sexes and species of mosquitoes. Mosquito News 19:144-147.

Focks, D. A. 1980. An improved separator for the developmental stages, sexes, and species of mosquitoes (Diptera: Culicidae). Journal of Medical Entomology 17: 567-568.

Gjullin, C. M., W. W. Yates, and H. H. Stage. 1950. Studies on Aedes vexans (Meig.) and Aedes sticticus (Meig.), flood-water mosquitoes, in the lower Columbia River Valley. Annals of the Entomological Society of America 43: 262-275.

Hedström-Ringvall, A., C. Kjörk, K. Pettersson, M. Engström, D. Wisaeus, N. Hjerdt, J. Berglund, and P.-E. Sandberg. 2017. Ekologiskt anpassad årsreglering av Dalälven. 2017 Länsstyrelsen Dalarna Rapport 09: 1-170.

Horsfall, W. R., and M. Trpis. 1967. Eggs of floodwater mosquitoes. X. Conditioning and hatching of winterized eggs of Aedes sticticus (Diptera: Culicidae). Annals of the Entomological Society of America 60: 1021-1025.

Horsfall, W. R., H. W. J. Fowler, L. J. Moretti, and J. R. Larsen. 1973. Bionomics and embryology of the inland floodwater mosquito Aedes vexans. University of Illinois Press, Champaign, USA. 211 pp.

Huang, Y.-J. S., S. Higgs, and D. L. Vanlandingham. 2017. Review: Biological control strategies for mosquito vectors of arboviruses. Insects 8: 21 .

Jaenson, T. G. T. 1986. Massförekomst av Aedes rossicus och andra stickmyggor vid Dalälven hösten 1985. Entomologisk Tidskrift 107: 51-52.

Johnson, B. J., S. N. Mitchell, C. J. Paton, J. Stevenson, K. M. Staunton, N. Snoad, N. Beebe, B. J. White, and S. A. Ritchie. 2017. Use of rhodamine B to mark the body and seminal fluid of male Aedes aegypti for mark-release-recapture experiments and estimated efficacy of sterile male releases. PLoS Neglected Tropical Diseases 11: e0005902.

Kittayapong, P., K. J. Baisley, V. Baimai, and S. L. O'Neill. 2000. The distribution and diversity of Wolbachia infections in Southeast Asian mosquitoes. Journal of Medical Entomology 37: 340-345.

Kittayapong, P., P. Mongkalangoon, V. Baimai, and S. L. O'Neill. 2002. Host age effects and expression of cytoplasmic incompatibility in field populations of the Wolbachia-superinfected Aedes albopictus. Heredity 88: 270-274.

Kittayapong, P., S. Ninphanomchai, W, Limohpasmanee, C. Chansang, U. Chansang, and P. Mongkalangoon. 2019. Combined Sterile Insect Technique and Incompatible Insect Technique: The first proof-of-concept to suppress Aedes aegypti vector populations in semi-rural settings in Thailand. PLoS Neglected Tropical Diseases 13(10): e0007771.

Knipling, E. 1955. Possibilities of insect control or eradication through use of sexually sterile males. Journal of Economic Entomology 48: 459-462.

Knipling, E. 1979. The basic principles of insect population suppression and management. USDA Agriculture Handbook No 512. Washington, DC, USA. 659 pp.

Knipling, E. 1998. Role of parasitoid augmentation and Sterile Insect Technique for area-wide management of agricultural insect pests. Journal of Agricultural Entomology 15: 273-301.

Krafsur, E. 1998. Sterile Insect Technique for suppressing and eradicating insect populations: 55 years and counting. Journal of Agricultural Entomology 15: 303-317.

Kuhn, R. 2002. Colonisation of the floodwater mosquito Aedes vexans (Meigen) (Diptera: Culicidae). European Mosquito Bulletin 12: 7-16.

Lagadic, L., M. Roucaute, and T. Caquet. 2013. Bti sprays do not adversely affect non-target aquatic invertebrates in French Atlantic coastal wetlands. Journal of Applied Ecology 51: 102-113.

Lagadic, L., R. B. Schäfer, M. Roucaute, E, Szös, S. Chouin, J. de Maupeou, C. Duchet, E. Franquet, B. le Hunsec, C. Bertrand, S. Fayolle, B. Frances, Y. Rozier, R. Foussadier, J.-B. Santoni, and C. Lagneau. 2016. No association between the use of Bti for mosquito control and the dynamics of nontarget aquatic invertebrates in French coastal and continental wetlands. Science of the Total Environment 553: 486-494.

Laven, H. 1967. Eradication of Culex pipiens fatigans through cytoplasmic incompatibility. Nature 216 : 383-384. 
Lees, R. S., D. O. Carvalho, and J. Bouyer. 2021. Potential impact of integrating the Sterile Insect Technique into the fight against disease-transmitting mosquitoes, pp. 1081-1118. In V. A. Dyck, J. Hendrichs, and A. S. Robinson (eds.), Sterile Insect Technique - Principles and practice in Area-Wide Integrated Pest Management. Second Edition. CRC Press, Boca Raton, Florida, USA.

Lees, R. S., B. Knols, R. Bellini, M. Q. Benedict, A. Bheecarry, H. C. Bossin, D. E. Chadee, J. Charlwood, R. K. Dabire, L. Djogbenou, A. Egyir-Yawson, R. Gato, L. C. Gougna, M. M. Hassan, S. A. Khan, L. L. Koekermoer, G. Lemperiere, N. C. Manoukis, R. Mozuraitis, R. J. Pitts, F. Simard, and J. R. L. Gilles. 2014. Review: Improving our knowledge of male biology in relation to genetic control programmes. Acta Tropica 132S: S2-S11.

Lindquist, D. A., M. Abusowa, and M. J. Hall. 1992. The New World screwworm fly in Libya: A review of its introduction and eradication. Medical and Veterinary Entomology 6: 2-8.

Lofgren, C. S., D. A. Dame, S. G. Breeland, D. E. Weidhaas, G. M Jeffery, R. Kaiser, H. R. Ford, M. D. Boston, and K. F. Baldwin. 1974. Release of chemosterilized males for the control of Anopheles albimanus in El Salvador. III. Field methods and population control. American Journal of Tropical Medicine and Hygiene 23: 288-297.

Lundqvist, A.-C., M. Widemo, and I. Lindquist. 2013. Förslag till hur myggproblemet vid Nedre Dalälven kan hanteras på lång sikt. Redovisning av ett regleringsbrevsuppdrag. Länsstyrelsen Gävleborg Rapport 500-8033-13.

Lundström, J. O., B. Niklasson, and B. D. Francy. 1990. Swedish Culex torrentium and Cx. pipiens (Diptera: Culicidae) as experimental vectors of Ockelbo virus. Journal of Medical Entomology 27: 561-563.

Lundström, J. O., J. Chirico, A. Folke, and C. Dahl. 1996. Vertical distribution of adult mosquitoes (Diptera: Culicidae) in southern and central Sweden. Journal of Vector Ecology 21: 159-166.

Lundström, J. O., Y. Brodin, M. L. Schäfer, T. Z. P. Vinnersten, and O. Ostman. 2010a. High species richness of Chironomidae (Diptera) in temporary flooded wetlands associated with high species turnover rates. Bulletin of Entomological Research 100: 433-444.

Lundström, J. O., M. L. Schäfer, E. Petersson, T. Z. P. Vinnersten, J. Landin, and Y. Brodin. 2010 b. Production of wetland Chironomidae (Diptera) and the effects of using Bacillus thuringiensis israelensis for mosquito control. Bulletin of Entomological Research 100: 117-125.

Mains, J. W., C. L. Brelsfoard, R. I. Rose, and S. L. Dobson. 2016. Female adult Aedes albopictus suppression by Wolbachia-infected male mosquitoes. Nature Scientific Reports 6: 33846.

Merdic, E., and T. Lovakovic. 2001. Population dynamic of Aedes vexans and Ochlerotatus sticticus in flooded areas of the River Drava in Osijek, Croatia. Journal of the American Mosquito Control Association 17: 275-280.

Minar, J., I. Gelbic, and J. Olejnicek. 2001. The effect of floods on the development of mosquito populations in the middle and lower river Morava Regions. Acta Universitatis Carolinae Biologica 45: 139-146.

Moretti, R., and M. Calvitti. 2012. Male mating performance and cytoplasmic incompatibility in a wPip Wolbachia trans-infected line of Aedes albopictus (Stegomyia albopicta). Medical and Veterinary Entomology 27: 377-386.

O'Connor, L., C. Plichart, A. Cheong Sang, C. L. Brelsfoard, H. C. Bossin, and S. L. Dobson. 2012. Open release of male mosquitoes infected with a Wolbachia biopesticide: Field performance and infection containment. PLoS Neglected Tropical Diseases 6: e1797.

Östman, Ö. 2013. Hävdens betydelse för mängden översvämningsmyggor - del 2. Länsstyrelsen Gävleborg Rapport 24: 1-13.

Östman, Ö., ̊̊. Wengström, U. Gradin, J. Wissman, M. Schäfer, and J. O. Lundström. 2015. Lower abundance of flood water mosquito larvae in managed wet meadows in the lower Dalälven floodplains, Sweden. Wetlands Ecology and Management 23: 257-267.

Patterson, R. S., D. E. Weidhaas, H. R. Ford, and C. S. Lofgren. 1970. Suppression and elimination of an island population of Culex pipiens quinquefasciatus with sterile males. Science 168: 1368-1369.

Pal, R. 1947. Marking mosquitoes with fluorescent compounds and watching them by ultra-violet light. Nature 160: 298-299.

Rasić, G., N. M. Endersby, C. Williams, and A. A. Hoffmann. 2014. Using Wolbachia-based release for suppression of Aedes mosquitoes: Insights from genetic data and population simulations. Ecological Application 24: 1226-1234.

Ritchie, S. A., M. Townsend, C. J. Paton, A. G. Callahan, and A. A. Hoffmann. 2015. Application of $w$ MelPop Wolbachia strain to crash local populations of Aedes aegypti. PLoS Neglected Tropical Diseases 9: e0003930. 
Schäfer, M. L., and J. O. Lundström. 2001. Comparison of mosquito (Diptera: Culicidae) fauna characteristics of forested wetlands in Sweden. Annals of the Entomological Society of America 94: 576-582.

Schäfer, M. L., and J. O. Lundström. 2014. Efficiency of Bti-based floodwater mosquito control in Sweden - Four examples. Journal of the European Mosquito Control Association 32: 1-8.

Schäfer, M. L., J. O. Lundström, and E. Petersson. 2008. Comparison of mosquito (Diptera: Culicidae) populations by wetlands type and year in the lower River Dalälven region, Central Sweden. Journal of Vector Ecology 33: 150-157.

Schäfer, M. L., Wahlqvist P., and J. O. Lundström. 2018. The Nedre Dalälven River landscape in central Sweden - A hot-spot for mosquito (Diptera: Culicidae) diversity. Journal of the European Mosquito Control Association 36: 17-22.

Sharma, V. P., R. S. Patterson, and H. R. Ford. 1972. A device for the rapid separation of male and female pupae. Bulletin of the WHO 47: 429-432.

Strugarek, M., H. Bossin, and Y. Dumont. 2019. On the use of the Sterile Insect Technique or the incompatible insect technique to reduce or eliminate mosquito populations. Applied Mathematical Modelling 68: 443-470.

Sudarić Bogojević, M., E. Merdić, and T. Bogdanović. 2011. The flight distances of floodwater mosquitoes (Aedes vexans, Ochlerotatus sticticus and Ochlerotatus caspius) in Osijek, Eastern Croatia. Biologia (Bratislava) 66: 678-683.

Trpis, M., and W. R. Horsfall. 1967. Eggs of floodwater mosquitoes (Diptera: Culicidae). XI. Effect of medium on hatching of Aedes sticticus. Annals of the Entomological Society of America 60: 11501152.

Trpis, M., and W. R. Horsfall. 1969. Development of Aedes sticticus (Meigen) in relation to temperature, diet, density and depth. Annales Zoologici Fennici 6:156-160.

Trpis, M., and J. A. Shemanchuk. 1970. Effect of constant temperature on the larval development of Aedes vexans (Diptera: Culicidae). Canadian Entomologist 102: 1048-1051.

(US-EPA) US Environmental Protection Agency. 2017. Final registration decision on the new active ingredient Wolbachia pipientis ZAP (wPip) strain in Aedes albopictus. PC Code: 069035. EPA Reg. Number: 89668-4. Document EPA-HQ-OPP-2016-0205-0034. Washington, DC, USA.

Verhulst, N. O., J. A. C. M. Loonen, and W. Takken. 2013. Advances in methods for colour marking of mosquitoes. Parasites \& Vectors 6: 200.

Vreysen, M. J. B., J. Gerado-Abaya, and J. P. Cayol. 2007. Lessons from Area-Wide Integrated Pest Management (AW-IPM) programmes with an SIT component: An FAO/IAEA perspective, pp 723744. In M. J. B. Vreysen, A. S. Robinson, and J. Hendrichs (eds.), Area-wide control of insect pests: From research to field implementation. Springer, Dordrecht, The Netherlands.

Waltz, E. 2017. US government approves 'killer' mosquitoes to fight disease. US Environmental Protection Agency will allow release of insects in 20 states and Washington DC. 06 November 2017. Nature News.

Werren, J. H., L. Baldo, and M. E. Clark. 2008. Wolbachia: Master manipulators of invertebrate biology. Nature Reviews Microbiology 6: 741-751.

Wilson, G. R., and W. R. Horsfall. 1970. Eggs of floodwater mosquitoes. XII. Installment hatching of Aedes vexans. Annals of the Entomological Society of America 64: 1644-1647.

Yamada, H., A. G. Parker, C. F. Oliva, F. Balestrino, and J. R. L. Gilles. 2014. X-ray-induced sterility in Aedes albopictus (Diptera: Culicidae) and male longevity following irradiation. Journal of Medical Entomology 51: 811-816.

Zhang, D., R. S. Lees, Z. Xi, K. Bourtzis, and J. R. L. Gilles. 2016. Combining the Sterile Insect Technique with the Incompatible Insect Technique: III - Robust mating competitiveness of irradiated triple Wolbachia-infected Aedes albopictus males under semi-field conditions. PLoS One 11(3): e0151864.

Zheng, X., D. Zhang, Y. Li, C. Yang, Y. Wu, X. Liang, Y. Liang, X. Pan, L. Hu, Q. Sun, X. Wang, Y. Wei, J. Zhu, W. Qian, Z. Yan, A. G. Parker, J. R. L. Gilles, K. Bourtzis, J. Bouyer, M. Tang, B. Zheng, J. Yu, J. Liu, J. Zhuang, Z. Hu, M. Zhang, J. T. Gong, X. Y. Hong, Z. Zhang, L. Lin, Q. Liu, Z. Hu, Z. Wu, L. A. Baton, A. A. Hoffmann, and Z. Xi. 2019. Incompatible and sterile insect techniques combined eliminate mosquitoes. Nature 572: 56-61. 